\title{
Intentional versus unintentional use of contingencies between perceptual events
}

\author{
KIETH A. CARLSON and JOHN H. FLOWERS \\ University of Nebraska, Lincoln, Nebraska
}

\begin{abstract}
In three experiments we studied human ability to use statistical contingencies between visual stimuli (flankers and targets) to improve performance in a letter-digit classification task. We compared the performance of explicitly informed subjects with that of subjects who were told nothing of the contingencies. Simultaneous presentation of flankers and targets (Experiment 1) produced evidence of unintentional contingency use by both informed and uninformed subjects. When stimuli on trial $n$ predicted target stimuli on trial $n+1$ (Experiment 2) there was no evidence of unintentional processes, but informed subjects showed strong evidence of using intentional prediction strategies. When flanker onset preceded target stimuli presentation (Experiment 3), evidence of contingency use by both informed and uninformed subjects was found, but the data illustrated qualitative differences in response style (e.g., speed-accuracy tradeoffs) between the two groups. Intentional and unintentional uses of contingencies between perceptual events are qualitatively distinct with respect to the time frame in which they can be applied and the performance patterns they produce. Finally, we argue that the unintentional processes studied here are implicit in nature.
\end{abstract}

The human ability to discover and use correlations between environmental events to facilitate performance has been documented innumerable times since the earliest days of experimental psychology. Early research on 'schedules of reinforcement illustrated the influence of environmental contingencies on human behavior. More recent work suggests that environmental contingencies can affect behavior in either of two ways: (1) by subjects intentionally using known contingencies to develop explicit strategies or (2) by an unintentional process sensitive to frequency and/or correlation guiding subjects' responses, often without their awareness. Mounting evidence suggests that these intentional and unintentional processes are distinct. Responses generated by explicit strategies are often qualitatively different in style from responses generated by other presumably implicit processes (Green \& Flowers, 1991). Implicit and explicit sensitivity to correlated structures may also be differently affected by experimental task manipulations such as imposition of an additional processing load (Curran \& Keele, 1993; Reber, 1993). It has also been suggested that overall performance of a given task may not be "entirely implicit" or "entirely explicit," but rather, it may result from a combination of these unintentional and intentional processes (Reber, 1993).

The notion of a continuum of implicit and explicit processes has been most strongly articulated by Reber (1993). He has asserted that learning about event struc-

The authors would like to thank D. Dulany and an anonymous reviewer for their comments on an earlier draft of this paper. Portions of the present data were presented at MPA, 1995. Correspondence should be addressed to K. A. Carlson, University of Nebraska, Lincoln, NE 68508-0308 (e-mail: kcarlson@unl.edu). ture may start as an implicit process but become increasingly explicit with repeated exposure to the stochastic relationship between the events. However, Reber has also noted that even when verbal expression of a contingency is given by subjects performing a task, the reported information does not necessarily match either observed performance or the actual stochastic relationships inherent in the task. This may indicate the control of implicit processes even after initiation of explicit learning processes.

Attempts at dissociating implicit and explicit learning processes have typically involved task manipulations such as secondary task imposition to presumably restrict the use of capacity-limited explicit representation (e.g., Curran \& Keele, 1993). We have chosen an alternative approach to examining the different properties of implicit and explicit representation of probability relationships. This approach involves comparing the performance of subjects who are completely informed about a probability rule through verbal instruction with subjects who are completely uninformed about the existence of stochastic relationships among the stimuli. Even though implicit and explicit representation of stochastic relationships may coexist during performance of a particular task, there may be situations under which implicit processes are more beneficial to performance (e.g., high-processing load) and vice versa (e.g., when stochastically related events are separated in time or by intervening events). Prior research from our laboratory using a computer game task in which screen events were correlated (Green \& Flowers, 1991) showed that both informed and uninformed subjects made use of the event probability relationship, but that response style (patterns of joystick manipulation) differed qualitatively for the two groups, and overall performance of the informed group was actually 
worse than that of the uninformed group. The performance decrement among the informed subjects may have reflected the increased processing load imposed by the need to keep the rule in working memory. Manipulation of instruction level in conjunction with task variables that affect processing load and temporal properties of the task would thus seem to hold promise for investigating the relative effectiveness of explicit versus implicit processing under differing task conditions.

\section{EXPERIMENT 1}

Miller (1987) demonstrated that flankers correlated with simultaneously presented targets can affect reaction times (RTs). In the present research, we used a similar flanker task that required subjects to classify target stimuli as letters or digits as quickly and accurately as possible. Targets were flanked on both sides by one of three symbols, each having a certain probability relationship with the target's category. Half the subjects were explicitly informed about the exact contingencies between the flankers and the target. The remaining subjects were told that the flanking forms were distractors and that they should try to ignore them.

\section{Method}

\section{Subjects}

Eighty undergraduate introductory psychology students fulfilled a course requirement by participating in a single session lasting approximately $1 \mathrm{~h}$.

\section{Stimuli and Task}

A VGA monitor controlled by a 386DX Gateway microcomputer and MEL software were used to present stimuli. Subjects saw letter or digit targets that were flanked on either side by symbols $(*$, @, or \#). Subjects pressed one key for letter targets and another for digit targets. The targets were A, B, C, D, E, F, G, H, J, 1, 2, 3, $4,5,6,7,8$, or 9 . RT and accuracy were recorded.

Subjects saw 15 sequences of 48 trials for a total of 720 trials, with each flanking symbol occurring 16 times per list. Subjects started each list "as soon as they felt ready." After the 5th and 10th sequences, subjects were encouraged to take "longer breaks" if they desired. Immediately after each key press, a fixation point $(+++)$ was presented for $750 \mathrm{msec}$ followed by the next stimulus.

The 15 sequences mentioned above were constructed so that one flanker (either* or @) was more often paired with letter targets and the other was more often paired with digit targets. The stimuli that were consistent with this contingency were consistent (C) trials. Stimuli that violated this contingency were violated (V) trials. The third flanker (\#), which was equally associated with both letters and digits, defined neutral $(\mathrm{N})$ trials. The number of $\mathrm{C}$ and $\mathrm{V}$ trials were either 24 and 8 , respectively, or 30 and 2, respectively. This resulted in a probability bias in which a particular flanker's appearance "predicted" the target's identity $75 \%$ or $93 \%$ of the time. Subjects experienced either $75 \%$ "valid" or $93 \%$ "valid" trial sequences.

Half the subjects were informed about the flanker-target contingencies (informed groups) and the other half were uninformed about them (uninformed groups). Subjects in the informed conditions were shown the actual contingencies between specific flankers and target categories; these subjects were also given the instruction, "You may find this information helpful." The subjects in the uninformed condition were told to "ignore the distractors" while responding as "quickly and accurately as possible" to the tar- get. The result was a $2 \times 2$ design with subjects experiencing the .75 or .93 bias level in combination with being completely informed or uninformed about the contingencies. The four conditions were labeled I75, U75, I93, and U93.

\section{Procedure}

Subjects were randomly assigned to one of the four conditions and run individually. The appropriate instructions were read aloud as subjects read the same inst ructions silently.

After completing the task, subjects were given one of two questionnaires, depending on whether they were informed or uninformed. The uninformed subjects were given a question sheet with the same questions that the experimenter had asked them to answer orally. The questionnaires included the following open-ended questions: "Did you notice any relationship between letters and flankers?" "Did you notice any relationship between digits and flankers?" Then the following more leading questions were asked: "Did you notice whether certain flankers were more likely to appear with letters than with digits?" "Did you notice whether certain flankers were more likely to appear with digits than with letters?"1 Informed subjects were asked the following three questions: "Did you use the provided information about the relationships between the flankers and the letters?" "Did you use the provided information about the flankers and the digits?" "Do you think knowing this information helped you perform better than if you had not been given this information?"

\section{Results and Discussion}

All RTs greater than 1,000 and less than $150 \mathrm{msec}$ were discarded. Trials resulting in errors were not used in the RT analysis. This resulted in less than $3 \%$ excluded data for each trial type.

Subjects experienced 15 sequences of 48 trials each for a total of 720 trials. The first 5 , second 5 , and final 5 sequences were each combined to form three analysis blocks. Mean RTs were calculated for each trial type, resulting in nine means per subject, one for each trial type in each block. These means constituted the data used in the subsequent RT analyses.

\section{RT Analysis}

Figure 1 displays the mean RTs $\times$ trial type for each of the four conditions. ${ }^{2}$ As can be seen in Figure 1, in all conditions subjects responded fastest to $C$ trials and slowest to V trials.

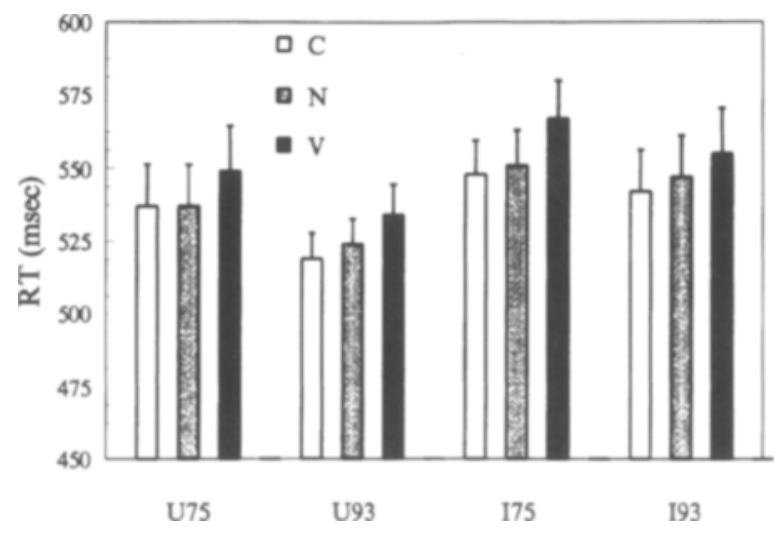

Figure 1. Mean reaction times (RTs) for each trial type in Experiment 1. Error bars depict $+1 S E$. 
The data from each condition were analyzed individually. In all four conditions, 3 (trial type) $\times 3$ (block) within-subject analyses of variance (ANOVAs) indicated significant trial type and block effects.

As shown in Figure 1, all four analyses revealed significantly faster responses to $\mathrm{C}$ trials than to $\mathrm{V}$ trials: U93 $\left[F(2,38)=6.30, M S_{\mathrm{e}}=600.27, p=.004\right] ; 193[F(2,38)=$ 3.61, $\left.M S_{\mathrm{e}}=749.31, p=.037\right] ; \mathrm{U} 75[F(2,38)=7.84$, $\left.M S_{\mathrm{e}}=387.79, p=.001\right]$; and $\mathrm{I} 75[F(2,38)=14.32$, $\left.M S_{\mathrm{e}}=396.75, p<.001\right]$. In all conditions, the majority of subjects were faster on $\mathrm{C}$ trials than on $\mathrm{V}$ trials. Specifically, 14 of 20 subjects showed this pattern in U93, I93, and U75. Seventeen of 20 subjects showed this pattern in I75. The mean RT differences between $\mathrm{C}$ and $\mathrm{V}$ trials for these groups were 15.7, 13.4, 12.6, and $19.7 \mathrm{msec}$, respectively.

Faster responses occurred in later blocks than in earlier blocks. ${ }^{3}$ This is common in RT tasks and will not be explored further.

\section{Error Analysis}

Figure 2 shows the proportion of errors $\times$ trial type for each condition. The proportion of errors across trial type was approximately equal for all conditions except for the $\mathrm{U} 75$ condition. Pairwise $t$ tests indicated that the percentage of errors was not different across $\mathrm{C}, \mathrm{N}$, and $\mathrm{V}$ trials for the $\mathrm{U} 93, \mathrm{I} 93$, and 175 conditions, with $t$ values from .04 to $1.94(p>.06)$.

In the U75 condition, subjects made significantly more errors on $\mathrm{V}$ trials than on $\mathrm{C}$ trials $[t(19)=2.15$, $p=.044]$, and significantly more errors on $\mathrm{V}$ trials than on $N$ trials $[t(19)=2.39, p=.027]$. Despite this difference in errors, it is noteworthy that subjects did not produce dramatically elevated error rates for the $\mathrm{V}$ trials, because dramatically elevated error rates for the $\mathrm{V}$ trials would indicate an intentional speed-accuracy tradeoff.

\section{Questionnaire Analysis for Uninformed Subjects}

To examine the possibility that the contingencies were discovered and then intentionally used to generate the trial type effect, subjects were classified into one of two

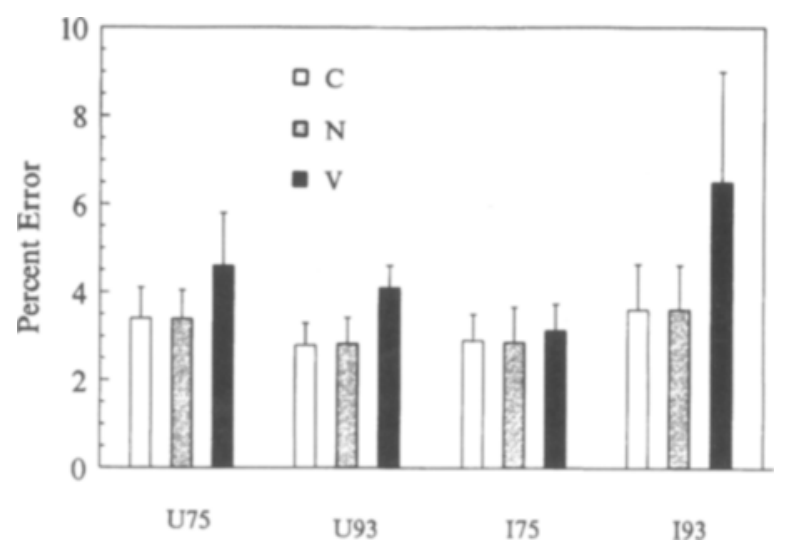

Figure 2. Percent errors for each trial type in Experiment 1. Error bars depict + $1 S E$. groups on the basis of the verbal reports prompted by the open-ended questions. ${ }^{4}$ Any subjects saying or writing anything consistent with the existing contingency during the experimental interview were classified into the verbally consistent group, with the remaining subjects forming the verbally inconsistent group. ${ }^{5}$ Figure 3 shows the mean RT $\times$ trial type for each group.

In the U75 condition, 12 subjects were classified into the verbally consistent group and 8 subjects formed the verbally inconsistent group. Although Figure 3 suggests slightly slower responses for the verbally consistent subjects, an RT comparison between these groups showed no main effect $\left[F(1,18)=.29, M S_{\mathrm{e}}=39,657.09, p=\right.$ $.598]$. More importantly, however, there was no trial type $\times$ group interaction $\left[F(2,36)=.12, M S_{\mathrm{e}}=406.67, p=\right.$ .889]. Mean V-C differences in RT between verbally consistent and verbally inconsistent subjects were of comparable magnitude, 14.0 and $10.4 \mathrm{msec}$, respectively. Thus the patterns of performance for these groups were not qualitatively different.

In the U93 condition, 10 of 20 subjects were classified into the consistent group. A 3 (trial type) $\times 3$ (block) $\times$ 2 (group) mixed ANOVA revealed no main effect for group $\left[F(1,18)=.76, M S_{\mathrm{e}}=14,484.5, p=.393\right]$. However, there was a significant interaction between group and trial type $\left[F(2,32)=3.57, M S_{\mathrm{e}}=528.64, p=.038\right]$. As Figure 3 suggests, the verbally consistent group did not show a significant trial type effect $[F(2,18)=.57$, $\left.M S_{\mathrm{e}}=471.03, p=.575\right]$, whereas the verbally inconsistent group did show a trial type effect $[F(2,18)=$ $\left.9.22, M S_{\mathrm{e}}=586.25, p=.002\right]$. The mean $\mathrm{V}-\mathrm{C}$ difference was only $5 \mathrm{msec}$ for the verbally consistent group and $25 \mathrm{msec}$ for the verbally inconsistent group. These results suggest that the use of contingencies between simultaneously presented stimuli can occur unintentionally. A reviewer of a previous version of this manuscript (Donald Dulany) suggested that one reason why the verbally consistent subjects showed little or no effect of the contingency is that with greater awareness of relationships between flankers and targets, those subjects were better able to follow the instructions to "ignore" the flankers. Whether or not verbally consistent subjects actually exhibited the degree of strategic control suggested above cannot be fully answered here, but these findings do indicate that the presence of active contingency awareness may override unintentional and automatic sensitivity to these perceptual correlations.

\section{Questionnaire Analysis for Informed Subjects}

In the informed conditions, subjects were asked whether or not they had tried to use the provided information about the flankers and targets. Subjects were then grouped on the basis of their answers.

In the I75 condition, only 6 subjects claimed to have used the information for at least some of the experiment. Because of the small size of this sample, a between-groups analysis was not performed. A within-group analysis of the RTs for the remaining 14 subjects, who stated they did not try to use the provided contingencies at all, pro- 

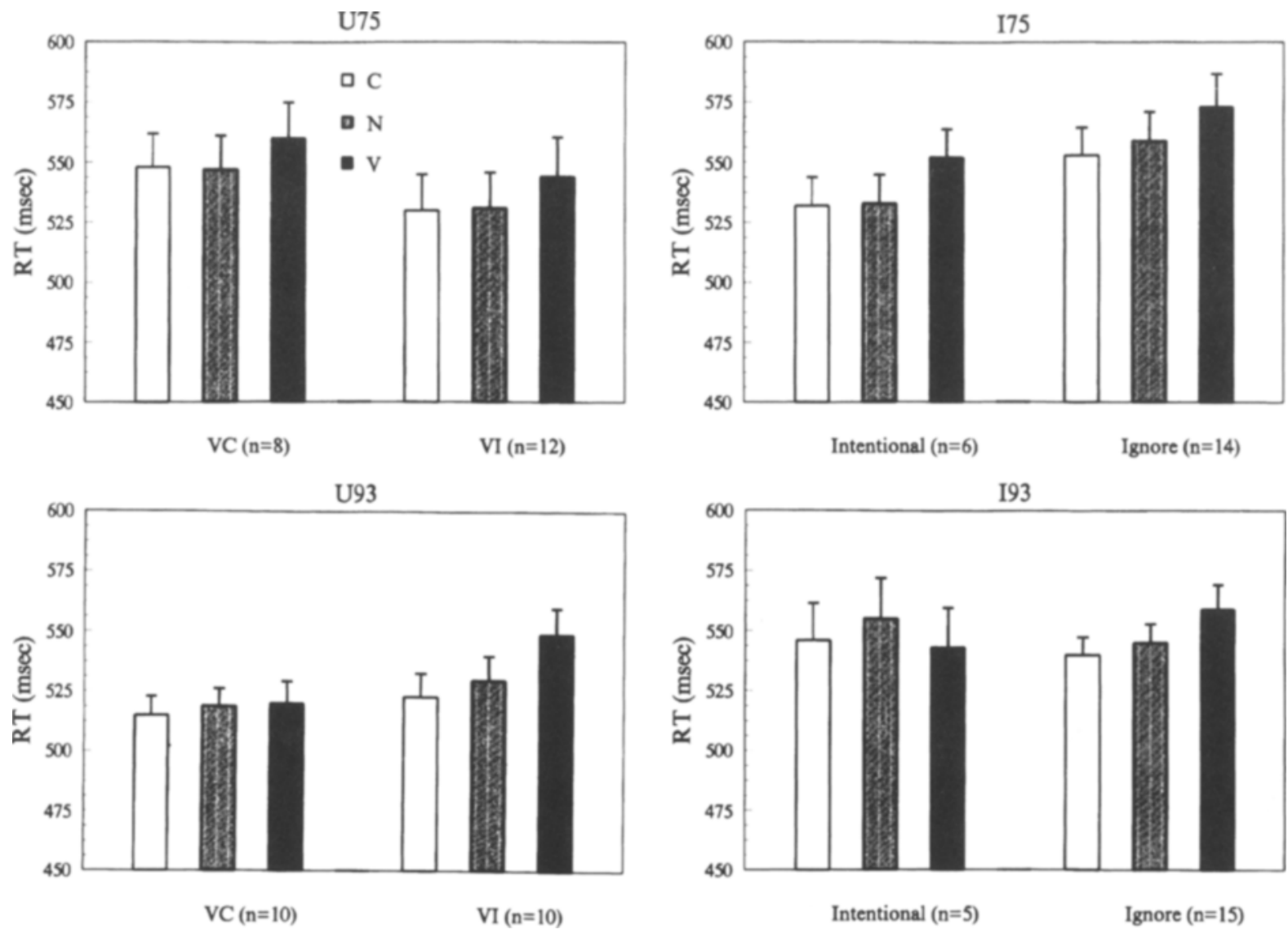

Figure 3. Mean reaction times (RTs) for subjects classifed into subgroups in Experiment 1. Error bars depict $+1 S E$.

duced a significant trial type effect $[F(2,26)=7.92$, $\left.M S_{\mathrm{e}}=551.65, p=.002\right]$. The mean RT difference between $V$ and $C$ trials was $19.79 \mathrm{msec}$ for this subset of subjects and $19.67 \mathrm{msec}$ for all 20 subjects. Thus, the removal of the 6 subjects claiming rule use had no effect on the mean $\mathrm{V}-\mathrm{C}$ difference.

In the 193 condition, 5 subjects claimed to have used the information for at least some of the experiment. The remaining 15 subjects, who denied having used the provided information, did produce a significant trial type effect $\left[F(2,28)=5.48, M S_{\mathrm{e}}=779.89, p=.010\right]$. The mean RT difference between $\mathrm{V}$ and $\mathrm{C}$.trials for this subset of subjects was $18.8 \mathrm{msec}$, whereas it was $13.39 \mathrm{msec}$ for all 20 subjects. In fact, the 5 supposedly rule-using subjects produced the following V-C RT differences: 7 , $-13,-9,-8$, and 9 msec.

\section{Questionnaire Responses and Error Patterns}

Table 1 displays the error percentages for $\mathrm{V}, \mathrm{N}$, and $\mathrm{C}$ trials on the basis of classification of subjects by questionnaire responses. Although the low overall frequency of errors and the uneven distribution of subjects according to questionnaire responses makes formal parametric analysis of error patterns tenuous, it is worth noting that error patterns are consistent with RT patterns. Differences in error rates between $\mathrm{V}$ and $\mathrm{C}$ trials were greater for ver- bally inconsistent uninformed subjects at both bias levels. Furthermore, at both bias levels, informed subjects who denied using the contingency produced greater error rate increases between $\mathrm{V}$ and $\mathrm{C}$ trials than did subjects who reported some contingency use.

In summary, these analyses demonstrate that subjects' performance was sensitive to flanker-target correlations. Furthermore, these analyses suggest that use of the statis-

Table 1

Error Rates and Verbal Responses by Condition

\begin{tabular}{llll}
\hline \multicolumn{1}{c}{ Condition } & \multicolumn{3}{c}{ Trial Type } \\
\cline { 2 - 3 } & $\mathrm{C}$ & $\mathrm{N}$ & $\mathrm{V}$ \\
\hline U75 & 3.4 & 3.5 & 4.1 \\
$\quad$ Verbally consistent & 2.2 & 1.8 & 3.9 \\
$\quad$ Verbally inconsistent & & & \\
U93 & 4.0 & 2.4 & 2.7 \\
$\quad$ Verbally consistent & 2.7 & 2.5 & 4.8 \\
$\quad$ Verbally inconsistent & & & \\
I75 & 3.6 & 3.7 & 3.2 \\
$\quad$ Contingency using & 2.6 & 2.5 & 3.1 \\
$\quad$ Contingency ignoring & & & \\
I93 & 2.1 & 2.4 & 2.7 \\
$\quad$ Contingency using & 4.1 & 4.0 & 7.8 \\
$\quad$ Contingency ignoring &
\end{tabular}

Note- $\mathrm{C}$, consistent; $\mathrm{N}$, neutral; $\mathrm{V}$, violated; $U$, uninformed; $\mathrm{I}$, informed. 
tical contingencies was largely unintentional. Since the questions were unexpected, one possible interpretation is that subjects entertained explicit target-flanker contingencies that had been "forgotten" prior to questioning. If uninformed subjects intentionally used explicit contingencies to produce the trial type effects, they presumably would have used them across the majority of the 720 trials they experienced. It seems highly unlikely that subjects would forget such simple "rules" if they had been actively attending to them for such an extended period of time. This "forgotten rules/contingencies" interpretation becomes even more unlikely given that explicitly instructed subjects who denied attempting to use the "rules" exhibited larger RT differences between V and $\mathrm{C}$ trials than did subjects who claimed intentional use of the "rules."

\section{Global Comparison of Informed and Uninformed Subjects}

A 3 (trial type) $\times 3$ (block) $\times 2$ (informed vs. uninformed) mixed ANOVA revealed no main effect of instruction $\left[F(1,78)=2.44, M S_{\mathrm{e}}=23,970.39, p=.122\right]$. The fact that there was a significant trial type effect $\left[F(2,156)=28.54, M S_{\mathrm{e}}=531.48, p<.001\right]$ while there was no significant trial type $\times$ instruction interaction $\left[F(2,156)=.18, M S_{\mathrm{e}}=531.48, p=.838\right]$ clearly demonstrates that informing subjects about the contingencies had no major impact on the RT differences they produced relative to those of uninformed subjects. This finding and the fact that removing the "most aware" subjects resulted in equal or greater estimates of contingency use leads us to conclude that an unintentional process was responsible for the trial type effects. If intentional processes were necessary for the trial type effects, one would expect little or no contingency use from the verbally inconsistent subjects, and this was clearly not the case. In order to conclude that intentional processes were responsible for the present effects, one would have to assume that (1) uninformed subjects acquired knowledge of the contingencies that was comparable to that held by completely informed subjects, (2) they actively used this acquired knowledge to generate the trial type effect across hundreds of trials even though the majority of informed subjects denied using the contingencies they were given, and (3) the uninformed subjects then forgot this vigorously applied knowledge in a period of less than a minute after the task. It seems more parsimonious to assume, as have Miller (1987) and others, that unintentional, even implicit processes are involved in using statistical contingencies between flankers and targets.

\section{EXPERIMENT 2}

Several probability learning experiments have shown that subjects were able to learn contingencies extending across as many as seven prior trials (Millward \& Reber, 1972). In Experiment 2, stimuli identical to those of Experiment 1 were presented, but the contingencies were between the flankers of trial $n$ and the target of trial $n+1$ rather than between the flankers and targets of the same trial. In addition to testing whether such contingencies can be learned either implicitly or explicitly, we were interested in testing whether the time separating the trials encourages informed subjects to use explicit strategies for predicting the target category that were not possible or practical with the simultaneous presentation of Experiment 1 (Taylor, 1977).

\section{Method}

\section{Subjects}

Forty-eight undergraduate introductory psychology students fulfilled a course requirement by participating in a single session lasting $1 \mathrm{~h}$.

\section{Stimuli and Task}

The same microcomputer and MEL software as those in Experiment 1 were used to present the same letters, digits, and flankers as those in Experiment 2. Subjects pressed one of two designated keys for letter targets and the other key for digit targets. RT and accuracy were recorded across 9 sequences of 101 trials each.

Subjects were instructed to initiate trials "as soon as they felt ready." After the third and sixth sequences, subjects were encouraged to take longer breaks (approximately 3-4 min). A fixation point $(+++)$ appearing for $750 \mathrm{msec}$ defined the intertrial interval, which commenced immediately after responses were given.

Probability bias (.90 or .78) and instruction (informed or uninformed) defined the four conditions. The flanker in trial $n$ predicted the target's category (letter or digit) in trial $n+1$ with either .90 or .78 reliability. As in Experiment 1, those trials that were consistent with the probability bias were $C$ trials and those that violated it were $\mathrm{V}$ trials. The \# flanker was statistically unrelated to trial $n+1$ targets and thus defined neutral trials. No correlations existed between simultaneously presented flankers and targets. For the .78 bias sequences, there were $150 \mathrm{C}$ trials, $102 \mathrm{~N}$ trials, and $48 \mathrm{~V}$ trials. For the .90 bias sequences there were $180 \mathrm{C}$ trials, 102 $\mathrm{N}$ trials, and $18 \mathrm{~V}$ trials. As in Experiment 1, the final manipulation was instruction. Subjects in the informed condition were given examples demonstrating how the flankers predicted the likely target category on the successive trial. Subjects in the uninformed condition were told to ignore the flankers, as in Experiment 1.

\section{Procedure}

Individual subjects were randomly assigned to conditions and appropriate instructions read to them as they read the identical instructions on the computer terminal. After completion of the task, informed and uninformed subjects were given different questionnaires. These questionnaires were identical to those used in Experiment 1 , except for modifications to reflect the $n+1$ relationship between the flankers and targets.

\section{Results and Discussion}

All RTs greater than $1,000 \mathrm{msec}$ were discarded. This resulted in less than $3 \%$ excluded data per trial type.

Subjects experienced a total of 909 trials; however, because of the $n+1$ contingency there were only 900 test trials. Trials were consolidated to form three analysis blocks. Mean RTs were calculated by block and trial type, resulting in nine means per subject, three trial types in each block. These means constituted the data used in the following RT analyses.

\section{RT Analysis}

Figure 4 displays the mean RTs $\times$ trial type for each condition. The graph suggests no trial type effects in the 
uninformed conditions and strong trial type effects in the informed conditions. The mean $\mathrm{V}-\mathrm{C}$ differences were .59 and $.95 \mathrm{msec}$ for the U78 and U90 conditions, respectively, but were 13.9 and $24.0 \mathrm{msec}$ for the 178 and I90 conditions, respectively.

Statistical analysis confirmed the above interpretation, revealing no trial type effects in U78 or U90 $[F(2,24)=$ $.16, M S_{\mathrm{e}}=286.36, p=.849$, and $F(2,22)=.02, M S_{\mathrm{e}}=$ $411.84, p=.978$, respectively]. Also supporting the above interpretation, the analysis revealed a significant trial type effect in $\mathrm{I} 78\left[F(2,20)=4.58, M S_{\mathrm{e}}=506.39\right.$, $p=.023$ ], with 7 of 11 subjects producing faster RTs on $\mathrm{C}$ trials than on $\mathrm{V}$ trials. A significant trial type effect was also found in $190\left[F(2,22)=4.54, M S_{\mathrm{e}}=1,357.02\right.$, $p=.022]$, with 7 of 12 subjects showing the $C$ faster than the $\mathrm{V}$ pattern. With the large informed $M S_{\mathrm{e}} \mathrm{s}$ relative to uninformed $M S_{\mathrm{e}} \mathrm{s}$ ( 506 vs. 286 for the .78 probabilities and 1,357 vs. 412 for the .90 probabilities), there is strong evidence of substantial individual differences among the subjects in the informed conditions. Individuals using the explicitly known contingencies in different ways could explain these differences. We will discuss this in detail below.

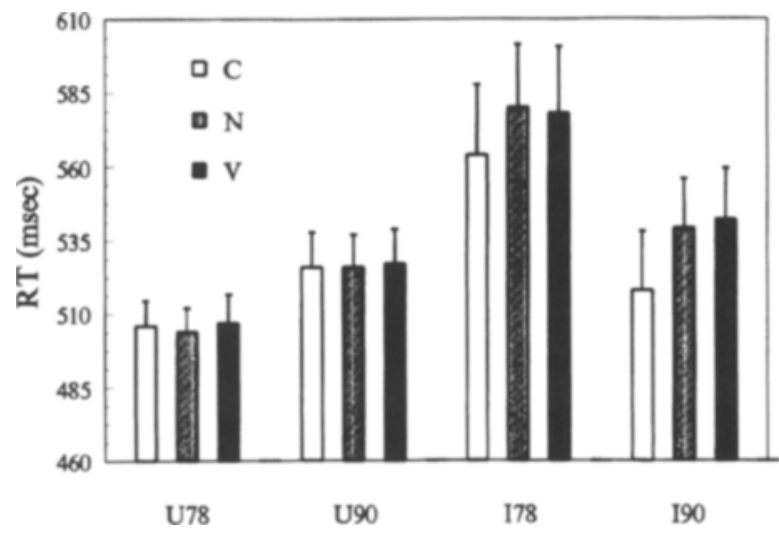

Figure 4. Mean reaction times (RTs) for each trial type in Experiment 2. Error bars depict $+1 S E$.

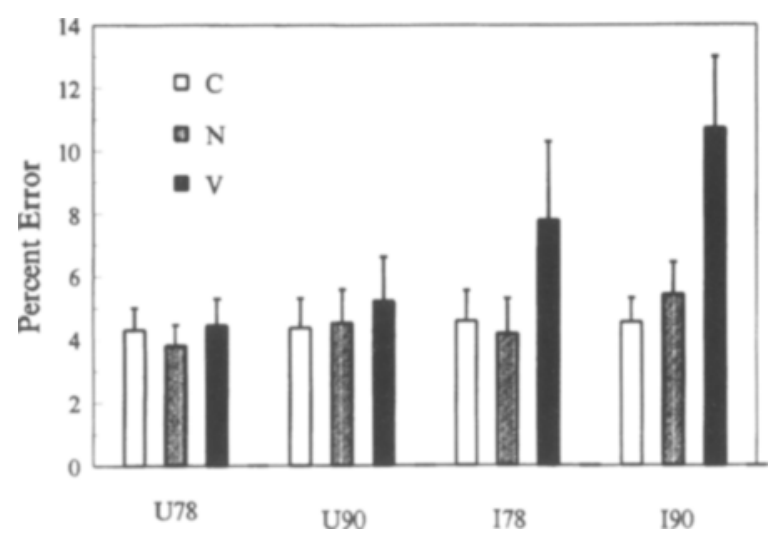

Figure 5. Percent errors for each trial type in Experiment 2. Error bars depict + $1 S E$.
Table 2

Error Rates and Reaction Time (RT) Differences for Individual Subjects (I78)

\begin{tabular}{crrrrr}
\hline & \multicolumn{3}{c}{ Trial Type } & & \\
\cline { 2 - 3 } Subject & $\mathrm{C}$ & \multicolumn{1}{c}{$\mathrm{N}$} & $\mathrm{V}$ & RT Difference \\
\hline $1^{*}$ & 7.82 & 12.50 & 28.57 & 52.44 \\
2 & 1.57 & .99 & 5.76 & 25.39 \\
3 & 7.38 & 4.00 & 6.85 & 19.68 \\
$4^{*}$ & 3.15 & 1.00 & 2.17 & 18.20 \\
$5^{*}$ & 8.89 & 7.21 & 8.33 & 4.37 \\
6 & 4.31 & 3.31 & 3.50 & -15.17 \\
7 & 1.38 & 1.00 & 0.00 & -12.37 \\
$8^{*}$ & 4.56 & 4.39 & 9.86 & 17.92 \\
$9^{*}$ & 2.94 & 4.33 & 10.87 & 50.82 \\
10 & 5.20 & 5.40 & 4.90 & -1.83 \\
11 & 3.42 & 2.01 & 4.90 & -6.37 \\
\hline
\end{tabular}

Note-C, consistenct; N, neutral; V, violated; I, informed. *These subjects indicated at least initial use of the provided information.

\section{Error Analysis}

Figure 5 displays the errors produced in each condition. As can be seen, the proportion of errors across trial type was not significantly different in either U78 nor U90. However, differences did appear in both of the informed conditions. In I78, the proportion of $\mathrm{V}$ errors was greater than the proportion of $N$ errors $[t(10)=2.48$, $p=.033]$, but it was not significantly greater than that in the $C$ trials $[t(10)=1.61]$. In the 190 condition, the proportion of $\mathrm{V}$ errors was greater than the proportion of $\mathrm{C}$ errors $[t(11)=2.44, p=.033]$.

An examination of individual subjects' error rates revealed considerable individual variation for the $\mathrm{V}$ trials among informed subjects (ranging from $0.0 \%$ to $28.6 \%$ for I78 and from $0.0 \%$ to $32.1 \%$ for 190 ). As for the RT effect mentioned above, the overall trend for higher errors in the V trials would appear to have been the contribution of a subset of the informed subjects. This pattern is examined in more detail in the following section.

\section{Individual Differences Among Informed Subjects}

Table 2 lists error rates as well as RT differences between $\mathrm{V}$ and $\mathrm{C}$ trials for each individual subject in $\mathrm{I78}$, and Table 3 lists equivalent data for I90. In addition, these tables indicate which of these subjects answered "yes" in their response to the questionnaire items, "Did you try to use the provided information about the relationship between (flankers and targets)?" For the 178 condition, 6/11 subjects denied using that information (Subjects 2, 3, 6, 7, 10, and 11). For these subjects the mean error rate was $4.31 \%$ for $V$ trials and $3.87 \%$ for $\mathrm{C}$ trials. For the same 6 (information-ignoring) subjects, the mean V-C RT difference was only $1.6 \mathrm{msec}$. For the remaining 5 subjects, who indicated that they at least initially had attempted to use the provided information, the mean error rate was $11.96 \%$ for $V$ trials and $5.47 \%$ for $\mathrm{C}$ trials. RT differences between $\mathrm{V}$ and $\mathrm{C}$ trials for these "rule-using" subjects was $28.75 \mathrm{msec}$.

For the I90 condition, only 2 of the subjects reported that they had not attempted to use the rule (Subjects 2 and 6 ). The mean error rate for these subjects was $10.19 \%$ for 
Table 3

Error Rates and Reaction Time (RT) Differences for Individual Subjects (I90)

\begin{tabular}{crrrr}
\multicolumn{5}{c}{ for Individual Subjects (I90) } \\
\cline { 2 - 4 } Subject & \multicolumn{3}{c}{ Trial Type } & . \\
\cline { 2 - 4 } & $\mathrm{C}$ & \multicolumn{1}{c}{$\mathrm{N}$} & $\mathrm{V}$ & RT Difference \\
\hline $1^{*}$ & 1.46 & 1.46 & 1.96 & 23.44 \\
2 & 4.27 & 3.28 & 5.56 & -3.11 \\
$3^{*}$ & 3.17 & 3.33 & 32.08 & 108.19 \\
$4^{*}$ & 4.66 & 5.61 & 7.41 & -12.75 \\
$5^{*}$ & .93 & 3.34 & 12.96 & 66.34 \\
6 & 11.44 & 10.30 & 14.81 & -20.50 \\
$7^{*}$ & 1.51 & 2.37 & 9.43 & 30.10 \\
$8^{*}$ & 4.23 & 6.99 & 17.65 & 38.65 \\
$9^{*}$ & 9.68 & 14.80 & 14.81 & -11.92 \\
$10^{*}$ & 2.92 & 2.10 & 0.00 & -9.31 \\
$11^{*}$ & 7.31 & 6.53 & 5.92 & 17.86 \\
$12^{*}$ & 3.04 & 5.02 & 5.68 & 61.02 \\
\hline
\end{tabular}

Note $\mathrm{C}$, consistent; $\mathrm{N}$, neutral; V, violated. *These subjects indicated at least initial use of the provided information.

the $\mathrm{V}$ trials and $7.86 \%$ for the $\mathrm{C}$ trials. Both of the subjects had faster times for $\mathrm{V}$ than for $\mathrm{C}$ trials, with a mean difference of $-11.8 \mathrm{msec}$. The remaining 10 subjects, who indicated having attempted to use the rule, produced a mean error rate of $10.79 \%$ for the $\mathrm{V}$ trials but only a $3.88 \%$ rate for the $\mathrm{C}$ trials. The mean RT V-C difference was $31.2 \mathrm{msec}$, despite the fact that 3 of these 10 subjects produced faster RTs to $\mathrm{V}$ than to $\mathrm{C}$ trials. However, one of these (Subject 9) stated that he/she eventually adopted an idiosyncratic (and erroneous) expectation of a pattern of sequential alternations of response keys.

This analysis strongly suggests that overt rule following among the instructed subjects may have been an optional strategy. But for those subjects who adopted it, the result was a characteristic pattern of substantial RT differences between $\mathrm{V}$ and $\mathrm{C}$ trials, coupled with a relatively dramatic increase in errors on $\mathrm{V}$ trials. This type of pattern, indicative of a strong response criterion bias in favor of "expected" trials, has been observed in a variety of previous experiments in which subjects were given a predictive rule and sufficient time between the relevant cue and the target stimulus to engage in a preparation strategy (Taylor, 1977). It would appear that one effect of the strength of the correlation between flankers and targets ( $78 \%$ vs. $90 \%$ ) may have been to encourage more subjects to use a prediction strategy in the high-bias condition relative to the low-bias condition.

\section{Summary}

Experiment 2 yielded a very different pattern of results than that of Experiment 1 . No evidence of learning flanker-target correlations was found for the uninformed subjects. Apparently implicit learning of correlations between perceptual events on one trial and events on the next trial does not seem to occur in this type of discrete reaction time task. However, at least a subset of the informed subjects demonstrated a substantial effect on both RT and error rates, suggesting that it is possible for subjects to use an explicit strategy to actively predict and prepare for stimuli and/or responses on the basis of events in a prior trial.

\section{EXPERIMENT 3}

In Experiment 3 we investigated a task that involved several of the properties of both Experiments 1 and 2. Target stimuli were delayed relative to the onset of flankers, thus providing preparation time for potential explicit strategies that was absent in Experiment 1. Correlations existed between flankers and targets within the same trial, so that the predictors and targets were not separated by an intervening response as they were in Experiment 2. Such conditions might be more conducive to both intentional and unintentional learning of correlations.

\section{Method}

\section{Subjects}

Eighty undergraduate introductory psychology students fulfilled a course requirement by participating in a single session lasting $1 \mathrm{~h}$

\section{Stimuli and Task}

The stimuli and the instructions given to subjects were identical to those given in Experiment 1. Subjects were to press the appropriate key on the basis of whether the target figure was a letter or digit.

\section{Procedure}

The procedure differed from that used in Experiment 1 in one important way. Rather than presenting the flankers and target simultaneously, the two flankers separated by a space appeared 750 msec prior to the "insertion" of the target between them. As in Experiment 1, the contingencies between the flankers and targets were either .75 or .93 . Subjects were randomly assigned to the different bias levels as well as to the informed and uninformed conditions.

\section{Results and Discussion}

All RTs greater than $1,000 \mathrm{msec}$ were discarded. This resulted in less than $2 \%$ excluded data for each trial type. The analyses were conducted as in the previous experiments.

\section{RT Analysis}

Figure 6 shows the mean RTs for each trial type $x$ condition. All conditions produced significant trial type effects with mean $\mathrm{C}$ trials faster than mean V trials: U75 $\left[F(2,38)=7.05, M S_{\mathrm{e}}=280.99, p=.002\right] ; \mathrm{U} 93[F(2,38)$ $\left.=10.78, M S_{\mathrm{e}}=965.97, p<.001\right] ; \mathrm{I} 75[F(2,38)=3.51$, $\left.M S_{\mathrm{e}}=459.18, p=.040\right]$; and $\mathrm{I} 93[F(2,38)=23.72$, $\left.M S_{\mathrm{e}}=3,417.14, p<.001\right]$. The majority of subjects were faster on C than on V trials; 15 of 20 in U75, 18 of 20 in U93, 14 of 20 in I75, and 19 of 20 in 193. The mean $\mathrm{V}-\mathrm{C}$ differences were $9.76 \mathrm{msec}$ for $\mathrm{U} 75,25.61 \mathrm{msec}$ for U93, $10.35 \mathrm{msec}$ for $\mathrm{I} 75$, and $73.5 \mathrm{msec}$ for 193 .

\section{Error Analysis}

Figure 7 indicates the proportion of errors $\times$ trial type in each condition. In U75, there was no difference between $\mathrm{V}(4.64 \%)$ and $\mathrm{C}$ trials $(3.56 \%)[t(19)=2.00, p=$ 


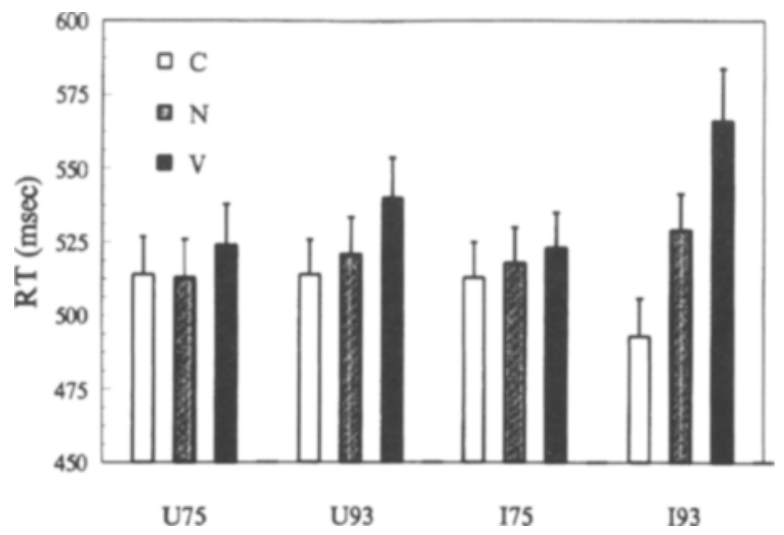

Figure 6. Mean reaction times (RTs) for each trial type in Experiment 3. Error bars depict $+1 S E$.

$.060]$. And in U93, no differences in errors were found between $\mathrm{V}(4.80 \%)$ and $\mathrm{C}(3.30 \%)$ trials $[t(19)=1.30$, $p=.208]$.

In I75, significantly more errors were produced on $\mathrm{V}$ trials $(4.27 \%)$ than on $\mathrm{C}$ trials $(2.88 \%),[t(19)=2.64, p=$ $.016]$. And in 193 , significantly more errors were produced on $\mathrm{V}$ trials $(8.11 \%)$ than on $\mathrm{C}$ trials $(3.15 \%)[t(19)=2.73$, $p=.013]$. Thus, the mean error rates in each group indicate that while significant increases in errors occurred in both informed conditions, they were absent in the uninformed conditions: The only substantial increase was in the 193 condition.

\section{Questionnaire Analysis for Uninformed Subjects}

The uninformed subjects' awareness of the existing relationships was similar to that of their peers in Experiment 1. As in Experiment 1, subjects were grouped according to their verbal reports (Figure 8).

In U75, 5 subjects' verbal reports included information consistent with the contingencies. The mean $\mathrm{V}-\mathrm{C}$ difference was $8.60 \mathrm{msec}$ for these verbally consistent subjects. The remaining 15 subjects produced a significant trial type effect $\left[F(2,28)=5.90, M S_{\mathrm{e}}=287.14, p=\right.$ .007 , with a mean $\mathrm{V}-\mathrm{C}$ difference of $10.14 \mathrm{msec}$. As in Experiment 1, subjects providing no information consistent with the contingencies were apparently using them. Furthermore, these $\mathrm{V}-\mathrm{C}$ differences were comparable in size to those obtained in Experiment 1.

In U93, 11 subjects reported information consistent with the contingencies. The mean $\mathrm{V}-\mathrm{C}$ difference was $33.32 \mathrm{msec}$ for these verbally consistent subjects, who had a significant overall trial type effect $[F(2,20)=7.67$, $\left.M S_{\mathrm{c}}=1,302 \cdot 19, p=.003\right]$. For the remaining 9 verbally inconsistent subjects, the overall trial type effect was marginally significant $\left[F(2,16)=3.60, M S_{\mathrm{e}}=495.87\right.$, $p=.051]$, and the $\mathrm{V}-\mathrm{C}$ difference of $16.19 \mathrm{msec}$ was comparable to the difference obtained in Experiment 1. The discrepancy in magnitude of the $\mathrm{V}-\mathrm{C}$ difference produced by the consistent subjects $(33.32 \mathrm{msec})$ relative to that produced by the inconsistent subjects $(16.19 \mathrm{msec})$ may indicate some intentional use of the time between flanker and target presentation on the part of the verbally consistent subjects.

\section{Questionnaire Analysis for Informed Subjects}

The subjects were grouped, as in Experiment 1, according to their reported use of the given probability information. In I75, 5 subjects claimed not to have used the information. The mean $\mathrm{V}-\mathrm{C}$ difference for these subjects was $4.43 \mathrm{msec}$. The remaining 15 subjects admitted at least some use of the provided information but denied having used the information throughout the trials. These subjects produced a significant trial type effect $[F(2,28)=3.83$, $\left.M S_{\mathrm{e}}=479.31, p=.034\right]$. The mean V-C difference was $12.33 \mathrm{msec}$ for these subjects. Many subjects noted that they had tried using the contingencies intentionally and had then abandoned this strategy because of high error rates.

In I93, 7 subjects claimed not to have used the information. The mean $\mathrm{V}-\mathrm{C}$ difference was $38.44 \mathrm{msec}$; however, with 1 subject removed, the difference became $17.76 \mathrm{msec}$. The remaining 13 subjects admitted having used the contingencies provided. These subjects produced an enormous $\mathrm{V}-\mathrm{C}$ difference of $92.38 \mathrm{msec}\left[F(2,24)=31.52, M S_{\mathrm{e}}=\right.$ $2,648.96, p<.001]$.

The salient pattern in these data is the wide range in the magnitude of the $\mathrm{V}-\mathrm{C}$ difference across groups as well as across subjects using generally more unintentional/implicit versus more intentional/explicit processing strategies. It would appear that when there is sufficient time for intentional contingency use, verbal reports of contingencies (or their use) are associated with large $\mathrm{V}-\mathrm{C}$ differences (i.e., generally in excess of $30 \mathrm{msec}$ ), whereas unintentional use by either informed or uninformed subjects leads to smaller $\mathrm{V}-\mathrm{C}$ differences, comparable to those obtained in Experiment 1 (i.e., $10-20 \mathrm{msec}$ ).

\section{Questionnaire Responses and Error Patterns}

Table 4 displays the error percentages for $\mathrm{V}, \mathrm{N}$, and $\mathrm{C}$ trials based on classification of subjects by questionnaire responses. Like larger V-C RT differences, larger V-C error rate differences were associated with questionnaire

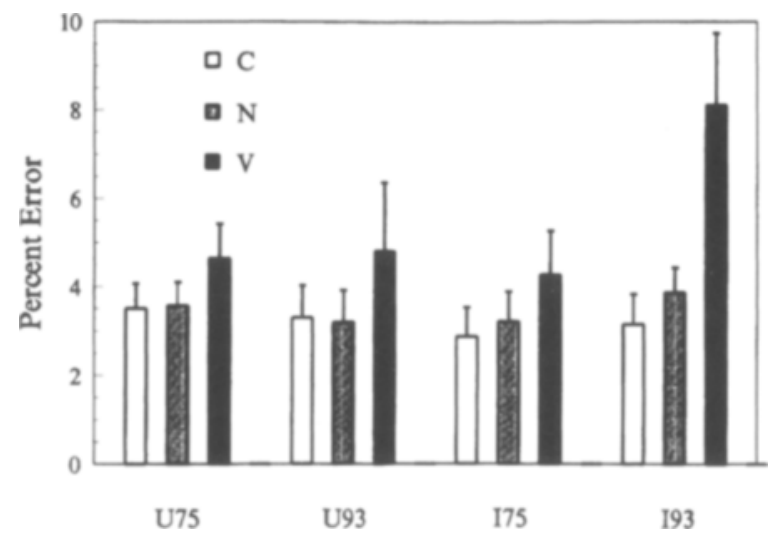

Figure 7. Percent errors for each trial type in Experiment 3. Error bars depict $+1 S E$. 

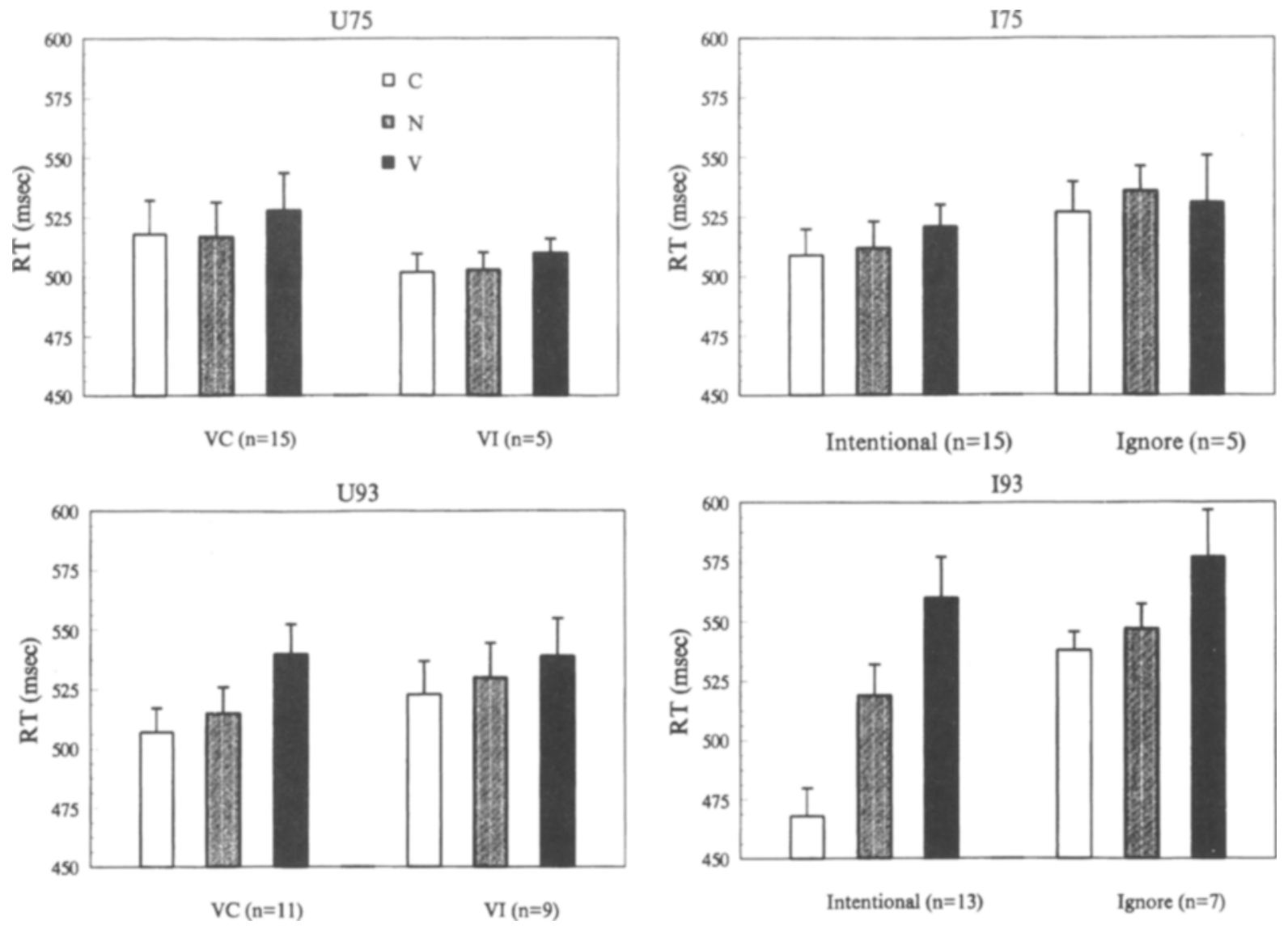

Figure 8. Mean reaction times (RTs) for subjects classified into subgroups in Experiment 3. Error bars depict $+1 S E$.

responses suggesting greater contingency awareness and/or use. This is particularly noticeable in 193, where subjects claiming to use the contingency produced a $9.4 \%$ error rate in $\mathrm{V}$ trials, whereas the contingency-ignoring subjects' error rate was $5.8 \%$.

In summary, it should be apparent from these data that inclusion of a short time delay between flankers and targets within the same trial permits both implicit and explicit learning of flanker-target contingencies. Verbal reports of contingency use were positively associated with greater $\mathrm{V}-\mathrm{C}$ differences. In addition, both verbal reports and performance patterns suggest that some uninformed subjects may have acquired an explicit verbal representation of the contingencies (particularly in the U93 condition).

\section{GENERAL DISCUSSION}

In the present experiments we investigated the differing consequences of explicit instruction describing specific stochastic relationships between events (informed conditions) versus instruction to ignore the existence of such relationships (uninformed conditions). In Experiment 1 , uninformed subjects were able to learn and use stochastic relationships between simultaneously presented flankers and targets with little or no verbal aware- ness of those relationships. In addition, subjects did not seem to gain further benefit from explicit instructions about flanker-target correlations. The informed subjects' verbal responses to questionnaires as well as their RTs and error rates across trial types suggest that these subjects abandoned the explicit use of the provided correlation information.

When the correlations were between flankers of trial $n$ and the target of trial $n+1$ (Experiment 2), uninformed

Table 4

Error Rates and Verbal Responses by Condition

\begin{tabular}{llcl}
\hline & \multicolumn{3}{c}{ Trial Type } \\
\cline { 2 - 4 } \multicolumn{1}{c}{ Condition } & $\mathrm{C}$ & $\mathrm{N}$ & $\mathrm{V}$ \\
\hline U75 & & & \\
$\quad$ Verbally consistent & 4.0 & 4.0 & 5.1 \\
$\quad$ Verbally inconsistent & 2.2 & 2.2 & 3.2 \\
U93 & & & \\
Verbally consistent & 3.2 & 2.9 & 5.3 \\
$\quad$ Verbally inconsistent & 3.4 & 3.6 & 4.1 \\
I75 & & & \\
Contingency using & 3.4 & 3.7 & 5.0 \\
Contingency ignoring & 1.5 & 1.8 & 2.2 \\
I93 & & & \\
$\quad$ Contingency using & 3.4 & 4.1 & 9.4 \\
Contingency ignoring & 2.7 & 3.5 & 5.8 \\
\hline
\end{tabular}

Note-C, consistent; $N$, neutral; $V$, violated. 
subjects showed no evidence of learning the correlations. However, at least some informed subjects produced large RT and error rate differences across trial types. Matching individual subjects' questionnaire responses with their RTs and error rates suggested that those subjects who claimed to use the correlations produced markedly longer RTs and substantially more errors on $\mathrm{V}$ trials relative to $\mathrm{C}$ trials. Furthermore, subjects in the .93 bias conditions appeared more likely to have chosen such an explicit strategy.

When the correlations were between flankers and targets of the same trial and the flankers' presentation preceded the targets' by $750 \mathrm{msec}$, but occurred within the same trial frame (Experiment 3), the uninformed subjects were again able to learn the stochastic relationships, as in Experiment 1. The informed subjects chose either to use an explicit strategy or to abandon the provided information. As in Experiment 2, this choice appears to have been influenced by the strength of the correlations, with the stronger correlations (.93) leading to more explicit strategy use than the weaker correlations (.75).

\section{Implicit Versus Explicit Use of Event Correlations}

The present experiments suggest important qualitative distinctions between the implicit and explicit (possibly rule-governed) use of information about probability relationships between perceptual events. The effective use of intentional strategies suggested by direct verbal instruction seems to depend on a time delay between the correlated events. However, such intentional strategies allow subjects to link information from an event on one trial to a consequential event on a subsequent trial, whereas implicit linking of these events in the absence of instructions does not seem to occur. In contrast, implicit learning and use of correlations between simultaneous perceptual events seems to occur, even though subjects appear unable (and certainly unwilling) to use a conscious expectancy strategy to link such events.

An important characteristic of the explicit correlation use (i.e., an intentional prediction strategy) is that the choice to employ it seems tied to the strength of the correlations. Inspection of questionnaire data from 178 (Experiment 2) and $I 75$ (Experiment 3 ) strongly suggested that these subjects did not use the probability information to the same extent that it was used by their higher probability counterparts (I90 and I93) because such a strategy would risk false-alarm errors on an unacceptably high proportion of trials. Several subjects specifically stated that use of the rule led to large error rates and therefore they did not use the rule. For example, 1 subject wrote that he tried to use the information initially, "I would have performed better without it, because with the information I tried to predict my response and then made errors." Another wrote, "It helped create mistakes." Still another wrote, "I didn't think it was helpful because I didn't use it after I got the wrong answers." Explicit instruction, therefore, may introduce the additional issue of costs and benefits of response biasing. Because of this, the precise wording of instructions to subjects about the potential usefulness of the probability information, as well as the degree to which speed or accuracy is emphasized may be quite critical in determining the pattern of results. Our subjects were simply told, "You may find [these correlations] helpful," and told them to respond as quickly and accurately as possible. Instructions that place more emphasis on speed and the importance of using the provided information might lead to greater intentional use of correlations of lesser strength. In our case, it is possible that the subjects in the $\mathbf{7 5}$ condition of Experiment 3 actually became "risk averse" because of our instructions.

\section{Processing Load and Explicit Rules}

The subjective comments of subjects in the informed condition clearly indicate that attempts to use explicit rules involved effort. The data clearly show that effective explicit rule usage requires time, as well. However, it should also be noted that across all three experiments, in 15 of the possible 18 comparisons between equivalent trial types, the informed subjects produced slower RTs than did their uninformed counterparts. ${ }^{6}$ Thus the trend toward slower overall responding for informed subjects suggests that providing explicit information can create an extra processing load, resulting in generally slower performance (Green \& Flowers, 1991). It thus might be argued that there are circumstances in which, for optimal performance, subjects are "better off not knowing."

\section{Implicit Learning of Event Correlations}

The experiments presented here clearly suggest that subjects' performance is influenced by relatively modest correlations between simultaneously presented flankers and targets (Experiment 1) and by correlations between targets and flankers that precede them by $750 \mathrm{msec}$ (Experiment 3 ). These influences seem to occur without explicit awareness of the contingencies or the intention to act on them. However, these influences were absent when correlated flankers and targets appeared in successive trials (Experiment 2), even though that situation is conducive to applying intentional predictive strategies for correlation use. Unlike sequence learning tasks, in which correlations between temporally separated events are learned, the type of implicit perceptual learning in the present flanker task may be limited to simultaneous or temporally overlapping events. It is possible that the perceptual learning involved in these flanker tasks reflects a "low-level" perceptual mechanism similar to that proposed by Treisman and her colleagues (Treisman \& Deschepper, 1994) to explain implicit learning of "unattended" nonsense forms. Future research is required to further define the boundary conditions for situations in which implicit learning of perceptual correlations occur. A systematic investigation of the influence of such factors as temporal and spatial separation of correlated events, the perceptual organization of events (e.g., Gestalt grouping), display clutter, and dual task processing load would seem to be worthwhile. Such research might help answer questions about the role of visual attention in such implicit learning. 


\section{REFERENCES}

Curran, T., \& Keele, S. W. (1993). Attentional and nonattentional forms of sequence learning. Journal of Experimental Psychology: Learning, Memory, \& Cognition, 19, 189-202.

GreEN, T. D., \& Flowers, J. H. (1991). Implicit versus explicit learning processes in a probabilistic, continuous fine-motor catching task. Journal of Motor Behavior, 23, 293-300.

MILLER, J. (1987). Priming is not necessary for selective-attention failures: Semantic effects of unattended, unprimed letters. Perception \& Psychophysics, 41, 419-434.

Millward, R. B., \& Reber, A. S. (1972). Probability learning: Contingent-event schedules with lags. American Journal of Psychology, 85, 81-98.

Reber, A. S. (1993). Implicit learning and tacit knowledge: An essay on the cognitive unconscious. New York: Oxford University Press.

TAYLOR, D. A. (1977). Time course of context effects. Journal of Experimental Psychology: General, 106, 404-426.

Treisman, A., \& DeschepPer, B. (1994, November). Object token, attention, and visual memory. Paper presented at the 35th annual meeting of the Psychonomic Society, St. Louis.

\section{NOTES}

1. Uninformed subjects were given two additional questions following those mentioned: (1) "Identify which of three flankers was more likely to occur with a given target category." (2) "Estimate the actual percentage of times a letter or digit would be associated with a given flanker." However, inspection of these data indicated that subjects found these questions difficult to interpret, so these data will not be described.
2. The RTs were collapsed across blocks for presentation in the figures since there were no significant interactions involving block.

3. The block effects for each condition were as follows: U93 $[F(2,38)$ $\left.=4.05, M S_{\mathrm{e}}=2,287.47, p=.025\right] ; \mathrm{I} 93\left[F(2,38)=13.12, M S_{\mathrm{e}}=\right.$ $1,068.29, p<.001] ; \mathrm{U} 75\left[F(2,38)=14.66, M S_{\mathrm{e}}=849.63, p<.001\right]$; and $\mathrm{I} 75\left[F(2,38)=20.19, M S_{\mathrm{e}}=989.51, p<.001\right]$.

4 . The questions were as follows: (1) "Did you notice any relationship between letters and particular flankers? If yes, describe what you noticed as completely as you are able." (2) The next question was identical to the first but referred to digits rather than letters. (3) "Did you notice whether a certain flanker was more likely to appear with a letter than a digit? If yes, which one?" (4) The final question was a digit version of the previous question.

5. This was an extremely conservative criterion for assessing verbal knowledge of the existing associations. No subjects provided a complete and accurate description of the stimulus structure. A typical "more accurate" statement was, "It seemed that similar figures appeared together like 9s and @ symbols." Respondents giving this type of response were assigned to the verbally consistent group if they witnessed the stimulus structure in which @ and digits were associated. Such verbal responses suggest that the majority of subjects in the verbally consistent group did not discover the general flanker-target associations; rather, they recalled frequent or "memorable" instances after being asked leading questions that encouraged them to "construct" educated guesses about the existing stimulus structure.

6. One exception occurred in 193 for $\mathrm{C}$ trials in Experiment 3, where subjects clearly took accuracy risks in order to hasten responses to predicted targets.

(Manuscript received September 26, 1994; revision accepted for publication August 28, 1995.) 